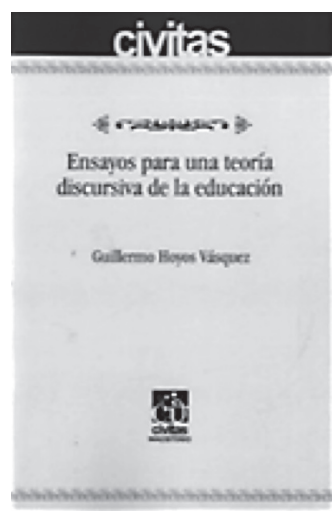

\title{
Reseña del libro \\ Ensayos para una teoría discursiva de la educación, \\ de Guillermo Hoyos-Vásquez
}

\begin{abstract}
Book Review Essays for a Discursive Theory of Education,
by Guillermo Hoyos-Vásquez

Compte-rendu du livre Essais pour une théorie discursive

de l'éducation, de Guillermo Hoyos-Vásquez

Resenha do libro Ensaios para uma teoria discursiva

da educação, de Guillermo Hoyos-Vásquez
\end{abstract}

Fecha de recepción: 13 DE MARZO DE 2014 / Fecha de aceptación: 20 DE MAYO DE 2014

Encuentre este artículo en http://magisinvestigacioneducacion.javeriana.edu.co/

doi:10.11144/Javeriana.M6-13.RLET

Escrita por Fabiola CABRA-TORRES

PONTIFICIA UnIVERSIDAD JAVERIANA Bogotá, Colombia

f.cabra@javeriana.edu.co

\section{Contenido}

Primera parte: Educación moral y formación ciudadana. Prólogo del libro: Pedagogía, discurso y poder. Educación para una cultura de los derechos humanos en Latinoamérica. La ética en los procesos de investigación. Competencia comunicacional y educación intercultural para una sociedad postsecular.

Segunda parte: Filosofía moral y política. Ética discursiva, derecho y democracia. Filosofía latinoamericana significa uso ético de la razón práctica. Filosofía para no filósofos. El diálogo: ética discursiva y política deliberativa.
Tercera parte: Sociedad civil y democracia. Descubrimientos, tolerancia, pluralismo, utopías. Violencia política y globalización: el derecho entre la solidaridad y el poder económico. Trampas a la moral. Redes y alianzas desde una teoría del actuar comunicacional.

Este libro reúne un conjunto de textos publicados y otros inéditos de Guillermo Hoyos-Vásquez (1935-2013), en torno a una teoría discursiva de la educación en un paradigma comunicacional.

Para desarrollar esta teoría discursiva como orientación de la educación contemporánea, el autor recurre a la filosofía moral y política, la fenomenología de Husserl, los tratados de E. Kant, la teoría de la acción

Para citar este artículo / To cite this article / Pour citer cet article / Para citar este artigo

Cabra-Torres, F. (2014). Reseña del libro Ensayos para una teoría discursiva de la educación, de Guillermo Hoyos-Vásquez. magis, Revista Internacional de Investigación en Educación, 6 (13), 185-187. 
comunicativa de J. Habermas y la idea de universidad, como fundamentos de su pensamiento.

En las tres partes en las que se organizan los ensayos que componen el libro, se encuentran planteadas algunas de sus más influyentes propuestas para repensar la educación como comunicación y fundamento de la ciudadanía en el marco de lo público, la sociedad civil y la democracia. Los doce trabajos recopilados por sus alumnos dan cuenta de algunos de los grandes temas que preocuparon al autor y permiten tejer y dilucidar la estructura discursiva y comunicacional de la educación en relación con las diferentes esferas de la vida social y de las ciencias sociales; diríamos que se trata de una educación que está inserta y que se reclama en la crisis de humanidad que marca nuestro destino como colombianos. Aquí se destacan algunas de estas ideas.

La obra inicia con el prólogo que escribiera hace veinte años para el libro Pedagogía, discurso y poder, en el cual plantea la primera idea generadora de su pensamiento educativo: "La educación y la pedagogía deben entenderse en el sentido fuerte de aplicación de la filosofía" (p. 17), para evitar que se positivicen e instrumentalicen. Para Guillermo HoyosVásquez, la filosofía tiene que aprender de la educación, en tanto ella misma es racionalidad comunicativa, intersubjetiva y dialogal.

En esta vía de argumentación, Hoyos-Vásquez desarrolla la idea de educación para un nuevo humanismo y relaciona la filosofía y el concepto clásico de paideia como humanitas, concepción del ser humano libre y autónomo. Desde la fenomenología, como crítica al positivismo en tanto colonización del mundo de la vida por el discurso de la ciencia y la tecnología, insiste en un proceso formativo que lleve a pensar en el hombre en toda su complejidad, en su contexto e historicidad, en su relación con la naturaleza y sus semejantes, más allá de la simple información y el aprendizaje de destrezas.

Se trata de emprender un desplazamiento paradigmático, que trasciende los humanismos tradicionalistas, al acudir a la racionalidad discursiva y dialógica y al paradigma del actuar comunicativo propuesto por Habermas. Para Guillermo Hoyos-Vásquez resulta muy potente este pensamiento que, desde la intersubjetividad, articula las dimensiones de lo moral, lo ético, lo político y los aportes del conocimiento científico como aspectos complementarios del progreso de la condición humana.

Esta idea constituye la base de una forma renovada de humanismo que, inspirada en la teoría del actuar comunicacional, define la naturaleza de la educación como lugar privilegiado para desarrollar la capacidad de comunicación de los humanos en la perspectiva de una sociedad democrática. De esta forma, Hoyos-Vásquez nos invita a comprender que la educación puede cumplir una importante función en el desarrollo de nuevas voces ciudadanas.

Esta relación íntima entre educación para la ciudadanía y el ejercicio de la democracia, en el horizonte de una sociedad que se construye basada en la justicia como equidad, es la base del nuevo humanismo como utopía viable, que el autor se propone desarrollar y mostrar como paradigma alternativo al discurso tecnológico de la educación. Para Guillermo Hoyos-Vásquez, este posicionamiento comprometido con la superación de desigualdades, exclusiones y discriminaciones de la sociedad implica ir más allá de posiciones unilaterales o dicotómicas que favorecen la ciencia y la tecnología o los valores; en cambio, propone la complementariedad necesaria y razonable entre el punto de vista moral y el de la ciencia y tecnología en el ámbito de la sociedad. 
Al explicitar la estructura comunicativa y discursiva de la educación, la reconoce como el camino para desarrollar los valores que fomentan la convivencia y motivan a una sociedad en procesos hacia la democracia y la paz. Para Hoyos-Vásquez, en Colombia, donde la violación de los derechos humanos proviene de la guerrilla, de los paramilitares, del narcotráfico o de las Fuerzas Militares, no se puede seguir pensando que la paz vendrá con el mayor control, la seguridad y la eliminación del otro, en lugar de más democracia. Por lo contrario, en una perspectiva radical, ante todo se requiere impulsar la participación de la sociedad civil, profundizar en el sentido de lo público como pluralismo democrático, superar el ejercicio de lo político como clientelismo corrupto y exacerbación de los intereses privados y fortalecer el Estado de Derecho para facilitar los consensos sobre mínimos constitucionales de convivencia pacífica y de cooperación.

En el contexto más amplio, Guillermo Hoyos-Vásquez advierte acerca de cómo la globalización neoliberal tiende a homogeneizar las sociedades, lo cual, en su opinión, motiva a buscar modos de entendimiento entre culturas que respondan a una ciudadanía cosmopolita en el sentido expuesto por J. Habermas y M. Nussbaum, entre otros. De ahí que se haga necesario un proceso de formación de competencias ciudadanas en perspectiva intercultural que contribuya a la construcción de un ethos mundial y motive a las nuevas generaciones al entendimiento mutuo, a la apreciación de la diversidad cultural, a la tolerancia como actitud fundamental en dos sentidos: para el reconocimiento del otro como diferente e interlocutor válido y como elemento clave en los procesos discursivos de la democracia. Esta sería una exigencia a la que deberían responder los modelos pedagógicos en el contexto de la multiculturalidad en sociedades globalizadas.

Para finalizar, como filosofo de la educación, Guillermo Hoyos-Vásquez profesó durante su vida, como testimonio intelectual, una visión comprometida y esperanzadora del trabajo filosófico en íntima relación con el ciudadano común y, en especial, con todos aquellos que han sido víctimas de la injusticia y la violencia política, religiosa y social y se les ha despojado de su dignidad. Para el autor:

[...] habría que destacar que la filosofía siempre se ha comprendido a sí misma no solo como crítica de situaciones históricas, sino también como autocrítica, lo que la capacita para mediar entre las culturas de los expertos y las necesidades de los ciudadanos, en especial en condiciones de colonización del mundo de la vida por la técnica, el mercado y la burocracia (p. 191).

\section{Sobre la autora}

Fabiola Cabra-Torres es doctora en Innovación Educativa. Es profesora asociada de la Facultad de Educación y del Doctorado en Ciencias Sociales y Humanas de la Pontificia Universidad Javeriana. Sus líneas de docencia e investigación se centran en estudios sobre la calidad de los sistemas de evaluación, el aprendizaje en la sociedad de la información y los métodos en Ciencias Sociales y Humanas.
Descripción del artículo | Article description | Description de I'article | Artigo descrição

Reseña del libro Ensayos para una teoría discursiva de la educación, de Guillermo HoyosVásquez.

Hoyos-Vásquez, G. (2012). Ensayos para una teoría discursiva de la educación. Bogotá: Cooperativa Editorial Magisterio. 293 pp. ISBN: 978-958-20-1057-7 